\title{
Students Perception About the Use of Jupyter Notebook in Power Systems Education
}

https://doi.org/10.3991/ijep.v11i1.14769

\author{
Nnamdi Nwulu, Uyikumhe Damisa, Saheed Lekan Gbadamosi ( $\left.{ }^{-}\right)$ \\ University of Johannesburg, Johannesburg, South Africa \\ gbadamosiadeolulgmail.com
}

\begin{abstract}
The purpose of this study was to examine students' computer attitudes and experience, as well as students' perceptions about the use of Jupyter notebook in the Electrical Engineering context, specifically in teaching Power Systems. The TAM approach is used to create a questionnaire with a 5-point Likert scale, with a decided midpoint of 2.5. This is used to determine the students' degree of acceptance and perception of the Notebook as a Teaching/learning tool for a power systems course. The Standard Package for Social Scientists (SPSS) was further used for descriptive statistical analyses. Results suggest that students hold favorable computer attitudes and perception about the use of the Jupyter notebook in power systems education. However, certain factors need to be considered when making the choice of software application to be used to facilitate students' learning. For instance, in this study, students did not consider the software to be highly useful in their future work life. Furthermore, the feedback from respondents can help software developers make informed decision about aspects of the application to improve.
\end{abstract}

Keywords - Student attitude and perception, Jupyter notebook, Free and OpenSource Software, Power system education

\section{$1 \quad$ Introduction}

ICT has become an indispensable part of learning in the academia today. Its educational uses can be potentially quite numerous [1]. The millennials are heavily in contact with technology through modern gadgets [2]. A number of studies have been done on the use of ICT in education. In [3], the impact of ICT on students' learning outcome was studied. With focus on the engineering discipline, the authors of [4] proposed a unified education platform integrating different software for practical training. Attitude is a key element in understanding educational processes in a learning environment [5]. The impact of ICT on students' learning experience is partly determined by their attitude and perception of its use. In order to assess this impact, therefore, it is important to investigate student's attitude and perception. Some research works have focus on these variables. The computer attitude, experience and perception with regards to the use of Arquimedes and Google Drive Spreadsheets in building engineering was studied in [6]. The authors of [7] presented a study on the attitudes and perceptions of students towards the Software Factory learning environment. The author of [5] investigated the effects of attitude with respect to learning in engineering drawing, taking engineering 
students as a case study. In this study, we investigate the perception of fourth-year students on the use of the Jupyter Notebook in power systems optimization. The Jupyter Notebook is an application that enables the creation and distribution of documents that may contain text, live code, graphs, equations, graphics and videos. The Notebook was employed in the delivery of practical tasks to fourth-year students of Power Systems at the University of Johannesburg, South Africa. It was well suited for the task as it provided an all-encompassing platform for the students to watch video tutorials, write, edit and run codes, and visualize graphical results. The practical tasks bordered on the economic dispatch (ED) problem of power systems. The ED of power systems is usually represented as an optimization problem which is solved by an optimization tool [8]. A Python-based optimization tool - Gekko is to be used to solve the ED problems of the practical tasks. To enable this, it is integrated into the Jupyter Notebook. In addition, the Notebook contained relevant video tutorials, links to external resources, as well as a solved ED example. This study was designed to explore the following objectives: 1 . To study students' attitudes towards the use of the Jupyter Notebook in power systems and how it impacts students' learning experience. 2. To assess students' perceptions about the use of Jupyter Notebook in power systems engineering.

\section{Conceptual Framework}

This study is concerned with the perception and attitude of students to the use of FOSS as a teaching and learning tool in power system education. Hence, there are two factors to consider, perception and attitude. Individual perception and attitude determine the mode of their thinking, action and inclination to respond to different challenges [9]. Therefore, student perception and attitude are key factors when introducing them to a new technology. A diverse means of acceptance and usage models of the technology was proposed to examine and predict the level of acceptance of the technology and its usefulness [10][11][12][13]. These models include Technology Acceptance Model (TAM) [10], which has been used by many technologies and its patterned to detect the level of acceptance of information technology. Furthermore, it is predicted that the results obtained from TAM model will have a great value on its users [10][11]. Other areas of applications include learning-assisting tool [12] and monitoring patient acceptance in remote locations [14]. In this study, the method used considered the TAM approach, such as perceived ease of use, usefulness, reliability, ability to foster learning and enjoyability of the software.

- Ease of use: This is perceived as the easiest means to understand, interact and become skillful with the new technology.

- Usefulness of software: A new software is perceived useful when a particular user believes that the software will improve research, work and have add value to them.

- Reliability of Software: This is expressed in term of output quality obtainable from the software with high level of accuracy.

- Ability to foster learning: This is perceived as a means of acquiring new skills and encourages lifelong learning.

- Enjoyable: Is the level of comfort the user enjoyed when using the new software aside from the reliable performance attributed to the software. 
Finally, the purpose of this study is to examine students' attitudes towards the use of FOSS as a teaching tool and to describe their perception about the use of Jupyter notebook in power system education. This is achieved using descriptive statistics such the frequency, means, standard deviation and percentage.

\section{Methods}

The data was collected using self-administered questionnaires. Analysis is a systematic and scientific approach to reaching a continuous conclusion by examining data. Hence, this section presents the method and material used for data analysis. The objective is to understand the student attitude and perception about the use of Jupyter notebook software in power systems education.

Table 1 show that a total number of 71 questionnaire were distributed. However, only forty-five (45) questionnaire, which represent $63.38 \%$ of the expected responses, was retrieved and suitable for analysis. Table 2 shows the characteristics of the students.

Table 1. Questionnaire analysis

\begin{tabular}{|l|c|c|}
\hline \multicolumn{1}{|c|}{ Questionnaires } & Frequency & Percentage (\%) \\
\hline Distributed & 71 & 71 \\
\hline Returned & 45 & 45 \\
\hline
\end{tabular}

Table 2. Respondents Characteristics

\begin{tabular}{|c|c|c|}
\hline & Frequency & Percentage \\
\hline \multicolumn{3}{|l|}{ Age } \\
\hline \multicolumn{3}{|l|}{ Below 15} \\
\hline \multicolumn{3}{|l|}{$16-20$} \\
\hline $21-25$ & 30 & 66.7 \\
\hline $26-30$ & 6 & 13.3 \\
\hline Missing & 9 & 20.0 \\
\hline \multirow{2}{*}{\multicolumn{3}{|c|}{$\begin{array}{c}\text { Total } \\
\text { Above } 30\end{array}$}} \\
\hline & & \\
\hline \multicolumn{3}{|l|}{ Gender } \\
\hline Male & 31 & 68.9 \\
\hline Female & 8 & 17.8 \\
\hline Missing & 6 & 13.3 \\
\hline Total & 45 & 100.0 \\
\hline \multicolumn{3}{|l|}{ First Time of registration for Power system } \\
\hline Yes & 35 & 77.8 \\
\hline No & 6 & 13.3 \\
\hline Missing & 4 & 8.9 \\
\hline Total & 45 & 100 \\
\hline \multicolumn{3}{|l|}{ Frequency in computer use (Hour/weeks) } \\
\hline \multicolumn{3}{|l|}{$<1$} \\
\hline \multicolumn{3}{|l|}{$1-5$} \\
\hline $6-15$ & 11 & 24.4 \\
\hline
\end{tabular}




\begin{tabular}{|c|c|c|}
\hline $15-30$ & 9 & 20.0 \\
\hline$>30$ & 21 & 46.7 \\
\hline Missing & 4 & 8.9 \\
\hline Total & 45 & 100.0 \\
\hline \multicolumn{3}{|l|}{ Computer and Internet access } \\
\hline I have a personal desktop/laptop with internet access & 21 & 46.7 \\
\hline I have a personal desktop/laptop with NO internet access & 9 & 20.0 \\
\hline I have access to a desktop/laptop at home with internet access & 3 & 6.7 \\
\hline I have access to a desktop/laptop at home with NO internet access & 8 & 17.8 \\
\hline I neither have access to a desktop/laptop and the internet & - & - \\
\hline Missing & 4 & 8.9 \\
\hline Total & 45 & 100 \\
\hline
\end{tabular}

\subsection{Participants}

The data from the student profile show a total of 45 power systems students from University of Johannesburg, South Africa. There are 31 male students (68.9\%), 8 female students (17.8\%) and 6 participants (13.3\%) failed to disclosed their gender. The sample age of the students shows that $66.7 \%$ of the students are within the age bracket of $21-25$ years, while $13.3 \%$ of the students are of $26-30$ years of age. This is an indication of the student's maturity to give a reliable information. The data available from the number of students that registered for power systems, shows that $77.8 \%$ of the students registered while $13.3 \%$ failed to register. All the participants were taking this course for the first time. This gives an indication of a lower level of student's awareness to power systems and higher level of student first time registration for power systems. Regarding the student accessibility to personal desktop/laptop, $46.7 \%$ have with internet connection while $20 \%$ are without internet connection. Similarly, $6.7 \%$ of the participants have access to a desktop/laptop at home with internet connection while $17.8 \%$ have access to a desktop/laptop at home but without an internet connection. This is an indication that a lot of the participants have good experience of computer.

\subsection{Instrumentation}

Questionnaire was administered to the participants which consists of three sections. The section A gives the socio-demographical information of the participants such as age, gender, course registration, accessibility to computer and internet. Section B provide information on the students experience with the use of Free and Open-Source Software (FOSS) as a tool for teaching and learning in Engineering Education and Power Systems. The participants can provide answer to this section using the following indicators $(5=$ Strongly Agree, $4=$ Agree, $3=$ Unsure, $2=$ Disagree, $1=$ Strongly Disagree). The five-point indicators allow the student to show their level of agreement or disagreement to the questions. Section C sought for the relevance and efficiency of the use of Jupyter Notebook in teaching Economic dispatch in the Power Systems using the same indicators as in Section B. This section was split into two: Teaching Method Using Free and Open-Source Software (FOSS) and Learning Using Free and Open-Source Soft- 
ware (FOSS). This section was used to analyse the efficiency especially when considering the ease of use, usefulness, reliability, ability to foster learning and enjoyability of the software to the students.

\subsection{Procedure}

Students were exposed to models of the economic dispatch problem of power systems. These models, which are usually represented as optimization problems, were solved using a python-based optimization tool called Gekko. The students were introduced to Gekko which is integrated into Jupyter Notebook with video tutorials and an economic dispatch example. Students could adjust the parameters in the examples and alter the coding in the Jupyter notebook to solve more practical tasks and the results could be observed in the graphical solutions. At the end of the course, the students were familiar with the use of Jupyter as a learning tool.

\subsection{Data analysis}

In order to justify the findings, the acquired data were analysed using descriptive measures such as the means frequency, standard deviation and percentage. This is achieved through Standard Package for Social Scientists (SPSS). Furthermore, fivepoint indicators ( $5=$ Strongly Agree, $4=$ Agree, $3=$ Unsure, $2=$ Disagree, $1=$ Strongly Disagree) was employed to allow participants to show their level of agreement or disagreement on the teaching method and learning method using the FOSS.

\section{$4 \quad$ Results and Discussion}

With a focus on the first objective of this study, this section presents an assessment of students' attitudes to the use of the Jupyter Notebook in a power systems course. As shown in the Table 3, under the first subsection, the recorded mean value for the statements is each higher than the midpoint used in this study, indicating a general acceptance of the use of the Jupyter Notebook for teaching. A more detailed examination of the "Rank" column of the Table shows the greatest level of consensus with regards to the flexibility and efficiency the Jupyter Notebooks added to their teaching experience. The statement - Jupyter notebook fostered active learning follows in ranking. The findings were further justified using standard deviation and mean ranking. Under the second subsection, the highest-ranking statements - I understood key concepts in economic dispatch because of the Software \& Jupyter Notebook software helped me to communicate, discuss and share knowledge with other students, have a higher mean than the highest recorded in the first subsection. 
Table 3. Students' perceptions on the use Jupyter Notebook for teaching and learning

\begin{tabular}{|l|c|c|c|}
\hline \multicolumn{1}{|c|}{ Teaching Method Using the Jupyter Notebook in a power systems course } & Mean & S.D & Rank \\
\hline Jupyteer notebook software made teaching sessions more flexible and efficient & 3.89 & 1.027 & 1 \\
\hline Jupyter notebook fostered better interaction with my teacher & 3.80 & .919 & 4 \\
\hline Using Jupyter notebook made the teaching session simulating and interesting & 3.84 & 1.086 & 3 \\
\hline Jupyter notebook fostered a love for the topic of economic dispatch & 3.80 & 1.036 & 4 \\
\hline Jupyter notebook fostered active learning & 3.88 & 1.131 & 2 \\
\hline \multicolumn{1}{|c|}{ Learning Using the Jupyter Notebook in a power systems course } & & & \\
\hline I comprehended better with the use of Jupyter Notebook software & 3.88 & .823 & 3 \\
\hline I understood key concepts in economic dispatch because of the Software & 3.93 & 1.100 & 1 \\
\hline $\begin{array}{l}\text { Jupyter Notebook software helped me to communicate, discuss and share } \\
\text { knowledge with other students }\end{array}$ & 3.93 & .985 & 1 \\
\hline The software increased my interest in learning & 3.74 & 1.136 & 5 \\
\hline $\begin{array}{l}\text { Jupyter Notebook software provided me with learning opportunities outside the } \\
\text { classroom }\end{array}$ & 3.79 & 1.081 & 4 \\
\hline
\end{tabular}

Table 4 presents descriptive statistics of respondents' feedback viz. mean, group mean, mean ranking and group mean ranking. As seen in the Table, the students' perception of the reliability of the software ranked the highest, while the "Ease of use" section ranked lowest.

These results are useful for both software developers and course facilitators. On the part of the developer of the application in question, the responses received could inform the necessary bug fixes or adjustments needed to be made to the software. Developers of similar products could also be guided by the feedback from respondents, leading to the development of highly accepted products. Course facilitators will find the feedback helpful while selecting software tools to facilitate learning.

Some limitations of this study are as follows:

1) The respondents to our questionnaire were students of a particular university, hence, the feedback may not be reflective of the attitude and perception of students from other learning institutions

2) Fourth-year students, being the respondents, have probably become comfortable with the use of ICT over the previous years, and are therefore more likely to have positive attitudes and perception than first-year students, for instance.

3) The study was carried out on Engineering students who probably have more exposure to ICT use than students in some other disciplines. 
Table 4. Students' attitude and perceptions on the use Jupyter Notebook for teaching and learning

\begin{tabular}{|c|c|c|c|c|}
\hline & Mean & $\begin{array}{c}\text { Mean } \\
\text { Ranking }\end{array}$ & $\begin{array}{l}\text { Group } \\
\text { Mean }\end{array}$ & $\begin{array}{c}\text { Group } \\
\text { Mean } \\
\text { Rank } \\
\end{array}$ \\
\hline \multicolumn{5}{|l|}{ Ease of Use } \\
\hline I found Jupyter software easy to use & 3.35 & 4 & \multirow[t]{5}{*}{3.60} & \multirow[t]{5}{*}{5} \\
\hline Jupytrer software is interactive & 3.67 & 3 & & \\
\hline $\begin{array}{l}\text { There were few learning hiccups encountered with the soft- } \\
\text { ware }\end{array}$ & 3.81 & 1 & & \\
\hline $\begin{array}{l}\text { I will find it easy to becomes skilful using the Jupyter soft- } \\
\text { ware }\end{array}$ & 3.21 & 5 & & \\
\hline The software has easy to understand visualisation tools & 3.79 & 2 & & \\
\hline \multicolumn{3}{|l|}{ Usefulness of Software } & \multirow[t]{6}{*}{3.73} & \\
\hline The software will be useful to me beyond the classroom & 3.81 & 1 & & \multirow[t]{5}{*}{4} \\
\hline The software will be useful to me in my work life & 3.65 & 5 & & \\
\hline The software will be useful to me in conducting research & 3.72 & 3 & & \\
\hline The software will be useful to me in industry & 3.72 & 3 & & \\
\hline The software has enormous practical value & 3.74 & 2 & & \\
\hline \multicolumn{3}{|l|}{ Reliability of the software } & \multirow[t]{6}{*}{4.00} & 1 \\
\hline I found the software to be reliable with no technical bugs & 3.98 & 3 & & \\
\hline I found login access to the software to be straightforward & 4.16 & 1 & & \\
\hline $\begin{array}{l}\text { I was impressed with the quality of the results (output) I } \\
\text { obtained using the software }\end{array}$ & 4.09 & 2 & & \\
\hline $\begin{array}{l}\text { I was satisfied that there were no inaccuracies when using } \\
\text { the software }\end{array}$ & 3.74 & 5 & & \\
\hline The software has reliable help/troubleshooting guides & 3.81 & 4 & & \\
\hline \multicolumn{5}{|l|}{ Ability to foster learning } \\
\hline The software helped clarify topics from the lecture room & 3.86 & 2 & \multirow[t]{5}{*}{3.81} & \multirow[t]{5}{*}{3} \\
\hline $\begin{array}{l}\text { The software motivated me to do further personal study and } \\
\text { research }\end{array}$ & 3.79 & 3 & & \\
\hline \begin{tabular}{|l|} 
The software improved my learning experience \\
\end{tabular} & 3.77 & 5 & & \\
\hline $\begin{array}{l}\text { The software helped me learn a new skill outside the class- } \\
\text { room }\end{array}$ & 3.95 & 1 & & \\
\hline The software encourages lifelong learning & 3.79 & 3 & & \\
\hline \multicolumn{5}{|l|}{ Enjoyable } \\
\hline I found using the software to be enjoyable & 3.86 & 2 & \multirow[t]{5}{*}{3.82} & \multirow[t]{5}{*}{2} \\
\hline I found the software to be fun with few challenges & 3.91 & 1 & & \\
\hline I found the software to be intuitive in its design & 3.86 & 2 & & \\
\hline I found the software to be flexible and interactive & 3.72 & 5 & & \\
\hline The software has comfortable graphics & 3.74 & 4 & & \\
\hline
\end{tabular}

\section{Conclusion}

In this study, statistical analyses indicate a positive attitude towards the use of the application, as well as a positive perception of its use. However, certain factors need to be considered when making the choice of software application to be used to facilitate students' learning. For instance, compared to other factors, students did not consider 
the software to be highly useful in their future work life. This, and other factors need to be taken into consideration by the course lecturer. Furthermore, software developers can be guided by the responses when performing software upgrades. While the results show a general acceptance of the use of the notebook, its adoption in engineering education would depend on the nature of the task to be achieved. For instance, the notebook is better suited for writing, editing and running of code than for hardware engineering. Results may also suggest that learners in the engineering discipline prefer all-encompassing learning tools like the Jupyter Notebook where learning, practice and solution to assignments can be achieved.

\section{References}

[1] Chergui, M., Tahiri, A., Chakir, A., \& Mansouri, H. (2020). Towards a New Educational Engineering Model for Moroccan University Based on ICT. International Journal of Engineering Pedagogy (iJEP), 10 (3), 49-63. https://doi.org/10.3991/ijep.v10i3.12421

[2] Tibola, L. R., Pereira, C. E., \& Tarouco, L. M. R. (2014). Improving performance to engineering students through virtual labs and its monitoring in cockpit. International Journal of Engineering Pedagogy (iJEP), 4(4), 43-50. https://doi.org/10.3991/ijep.v4i4.3957

[3] Zweekhorst, Marjolein B. M., and Jeroen Maas. (2015). ICT in Higher Education: Students Perceive Increased Engagement. Journal of Applied Research in Higher Education 7 (1): 2 18. https://doi.org/10.1108/jarhe-02-2014-0022

[4] Khoroshko, L., Ukhov, P., \& Khoroshko, A. (2018). The Use CAD/CAE Systems to Create E-Learning Courses on Technical Subjects at University. International Journal of Engineering Pedagogy, 8(2), 64-71. https://doi.org/10.3991/ijep.v8i2.8134

[5] Azodo, A. P. (2016). Attitude of engineering students towards engineering drawing: A case study. Int. J. Res. Studies in Edu, 6(1), 71-84.

[6] Chiner, E., \& Garcia-Vera, V. E. (2017). Student computer attitudes, experience and perceptions about the use of two software applications in Building Engineering. European Journal of Engineering Education, 42(6), 1455-1466. https://doi.org/10.1080/03043797.2017. $\underline{1306025}$

[7] Ahmad, M. O., Liukkunen, K., \& Markkula, J. (2014, April). Student perceptions and attitudes towards the software factory as a learning environment. In 2014 IEEE Global Engineering Education Conference (EDUCON) (pp. 422-428). IEEE. https://doi.org/10.1109/ educon.2014.6826129

[8] S. L. Gbadamosi, N. I. Nwulu, and Y. Sun, "Multi-objective optimisation for composite generation and transmission expansion planning considering offshore wind power and feedin tariffs," IET Renew. Power Gener., vol. 12, no. 14, pp. 1687-1697, 2018. https://doi.org/ 10.1049/iet-rpg.2018.5531

[9] Richardson, Virginia. (1996). The Role of Attitudes and Beliefs in Learning to Teach. In Handbook of Research on Teacher Education, edited by John Sikula, 102-119. New York, NY: Macmillan.

[10] Davis, Fred. D. (1989). Perceived Usefulness, Perceived Ease of Use, and User Acceptance of Information Technology. MIS Quarterly 13 (3): 319-340. https://doi.org/10.2307/249008

[11] Davis, Fred D., Richard P. Bagozzi, and Paul R. Warshaw. (1992). Extrinsic and Intrinsic Motivation to Use Computers in the Workplace. Journal of Applied Social Psychology 22: 1111-1132. https://doi.org/10.1111/j.1559-1816.1992.tb00945.x 
[12] Liaw, Shu-Sheng, Weng-Cheng Chang, Wu-Hsiung Hung, and Hsiu-Mei Huang. (2006). Attitudes Toward Search Engines as a Learning Assisted Tool: Approach of Liaw and Huang's Research Model. Computers in Human Behavior 22 (2): 177-190. https://doi. org/10.1016/j.chb.2004.09.003

[13] Venkatesh, Viswanath, Michael G. Morris, Gordon B. Davis, and Fred D. Davis. (2003). User Acceptance of Information Technology: Toward a Unified View. MIS Quarterly 27 (3): 425-478. https://doi.org/10.2307/30036540

[14] Giger, Jarod T., Natalie D. Pope, H. Bruce Vogt, Cassity Gutierrez, Lisa A. Newland, Jason Lemke, and Michael J. Lawler. (2015). Remote Patient Monitoring Acceptance Trends among Older Adults Residing in a Frontier State. Computers in Human Behavior 44: 174 182. https://doi.org/10.1016/j.chb.2014.11.044

\section{Authors}

Nnamdi Nwulu, Uyikumhe Damisa and Saheed Lekan Gbadamosi are from University of Johannesburg, Auckland Park 2006, South Africa.

Article submitted 2020-04-11. Resubmitted 2020-05-27. Final acceptance 2020-05-27. Final version published as submitted by the authors. 